\title{
Deployment limiting mental health conditions in us military personnel deployed to combat theaters: predictors of theater mental health evacuation
}

\begin{abstract}
Objective: Military sponsored personnel deploying to combat theaters undergo medical and behavioral health screening prior to deployment, ensuring a healthy fighting force is deployed.

Methods: Retrospective review of combat theater deployed personnel presenting in theater for mental health treatment were screened for the presence theater limiting mental health conditions that were present prior to combat deployment. Rates were retrospectively established for patients who could be treated in theater $(\mathrm{N}=511)$ compared to those that necessitated theater medical evacuation $(\mathrm{N}=123)$ due to psychiatric decompensation.

Findings: 50.1 percent of those medically evacuated had a previously identified theater limiting mental health condition, statistically different than those with a newly identified mental health condition treated in theater $(\mathrm{P}<.0001)$. Those with retrospectively determined medical screening failures were 52 times more likely to evacuated (OR 52.61, 95\% CI 25-108) than those without. This study demonstrates potential support of the utilization of existing pre-deployment medical screening procedures.
\end{abstract}

Keywords: theater evacuation, mental health, waivers, deployment, deployment limiting, combat theater, medevac
Volume 2 Issue 4 - 2015

\author{
Eve Weber,' David KWeber \\ 'Clinical Psychologist, USA \\ 2Psychiatrist, USA
}

\begin{abstract}
Correspondence: Eve G Weber, Clinical Psychologist, currently Director of Williamsburg Webers, PLC a Mental Health Service, I00IA Richmond Road, Suite 2E Williamsburg,
\end{abstract} Virginia 23I85, USA, Email DrEve@WMBGWebers.com

Received: March 02, 2015 | Published: March 26, 2015

\section{Introduction}

Combat operations are inherently challenging and place warriors under stress that can tax the resiliency of those subjected to these environments. To facilitate positive outcomes and maintain the operational effectiveness of the fighting force, the US Department of Defense publishes guidance to its subsidiaries defining combat theater deployment limiting medical and psychiatric conditions. ${ }^{1}$ The United States Central Command (USCENTCOM) publishes specific criteria for theater limiting medical and psychiatric conditions entitled "USCENTCOM Individual protection and individual unit deployment policy message" ${ }^{2}$ which is regularly updated to reflect current best practices. These standards are required to be applied to all military and civilian personnel ordered to conduct operations within the USCENTCOM area of responsibility utilizing a process where each individual is medically screened prior to deployment. This process, due to the sheer volume of evaluations and the breadth of medical care provided, is highly dependent upon voluntary disclosure during these exams and thus prone to under-reporting. The purpose of this study was to define the prevalence of pre-deploymentt heater limiting psychiatric conditions (or treatment) in combat theater deployed personnel who were evaluated by mental health providers. Further, this study attempted to define the prevalence of screening omissions for combat theater entry with theater limiting mental health conditions in patients evaluated in theater who eventually required theater evacuation.

Medical evacuation from combat operations is not a new concept and has its roots in the archives of combat operations. ${ }^{3}$ Medical evacuations have been accomplished throughout history initially using human assistance, and then animal assisted progressing to vehicular assisted and most recently aeromedical evacuation. Aeromedical evacuations of casualties were reportedly first utilized in the United States in 1910 as a means of expediting medical evacuations. ${ }^{4}$ Since
1949, the United States Department of Defense (DoD) policy has dictated use of airlift for the sick and wounded whenever possible and remains the standard of combat theater medical evacuation throughout the World.

Theater medical evacuation for mental health reasons is not a novel concept. Compared with previous conflicts, data from Operation Iraqi Freedom and Operation Enduring Freedom suggest a shift in injury patterns. ${ }^{5}$ In World War I, the three leading admission categories for US Naval and Marine forces, in descending order, were respiratory disease, infectious disease, and gastrointestinal disorders, with mental illness ranking eleventh. For both World War II and the Korean War, the top three causes of hospital admissions were respiratory disease, infectious disease, and non-battle-related injuries, with psychiatric disorders unchanged in ranking. By the Vietnam War, non-battle related injuries had supplanted respiratory and infectious disease as the leading cause of hospital admissions, with psychiatric illness edging up to sixth. ${ }^{6}$ During the Persian Gulf War, the top two reasons for admission of US Army service members to hospitalization were injury and other musculoskeletal disorders, with mental illness ranking eighth. ${ }^{7}$ The increasing and disproportionate consumption of resources by non-battle-related injuries is not unique to US forces. In British troops stationed in Bosnia during peak levels of combat in 1996, the top four reasons for hospital admission were musculoskeletal, dermatological, gastrointestinal, and psychiatric disorders. However, Operation Iraqi Freedom and Operation Enduring Freedom differ from previous conflicts in the length of the operations, the higher mean age and proportion of reserve service members, the number of repeat deployments, and the widespread availability of rapid communication. ${ }^{5}$

Published accounts during the United States Vietnam War indicated that the proportion of psychiatric illness in aeromedically evacuated patients was 12.9 percent and have been proportionate and 
relatively stable over time. More recently, in a descriptive analysis of 11, 183 U.S. military evacuees from the war in Iraq from January to December 2003 found 6.9 percent were psychiatric patients. ${ }^{8}$ Data published from November 2001 until July 2004 from the same area of operations indicated a psychiatric aeromedical evacuation rate of 10 percent. ${ }^{9}$ Cohen et al., ${ }^{5}$ published a review of aeromedical evacuations from OIF and OEF that demonstrated in increasing proportion of psychiatric evacuations culminating in rates of 14 and 11 percent respectively in 2007 . Additionally, the return to combat operations once a psychiatric patient is medically evacuated has been demonstrated to be low, between 6 and 13 percent, depending on the diagnostic category.

\section{Military policies and procedures}

Pre-deployment screening of service members is utilized to provide a healthy fighting force. Deployment limiting medical and psychiatric conditions for service members and DoD civilian employees is mandated by DoD instruction 6490.07. This instruction establishes policy, assigns responsibilities, and provides distinct procedures for ensuring that Service members deployed and deploying on contingency deployment are medically able to accomplish their duties in deployed environments.

Pre-deployment screening is used to determine if a service member has amedical condition of such a nature or duration that an unexpected worsening is likely to have a grave medical outcomeor negative impact on mission execution. ${ }^{10}$ The determination of suitability for combat theater deployment is made by a Pre-Deployment Medical Evaluator who determines, based upon best medical knowledge that a condition is stable for deployment and not reasonably anticipated to worsen during the deployment in light of physical, physiological, psychological and nutritional effects of the duties and location. Medical evaluators must consider the effect of climate, rations, housing, duty assignment, family separation, individual augmentee (deploying separate from a more cohesive unit), and medical services available in theater when deciding whether an individual with a specific history and medical condition is deployable. ${ }^{11}$ In general, it is required that individuals with conditions that may preclude deployment shall not deploy unless a waiver is granted via the USCENTCOM Surgeon via Waiver Application. ${ }^{2}$ Clearly stated in this doctrine is that a Profile does not constitute a theater entry Waiver of the USCENTCOM standards. USCENTCOM provides its commander's guidance on deployment limitingmedical and psychiatric conditions as a means of providing guidance on deployment to their theater of operationsentitled "USCENTCOM Individual protection and individual unit deployment policy message". This guidance defines the medical conditions that may be deployment limiting and procedures to apply for waivers of these medical conditions should certain criteria be met. These theater deployment limiting criteria are applied to all deploying personnel prior to theater entry during pre-deployment screenings following patient administered questionnaires about their medical and psychiatric history. ${ }^{2}$ Failures of this process allow personnel to enter combat theaters without adequate medical clearance and are thus termed "MOD-10 Failures".

Medical and psychiatric screening examinations prior to deployment may find a variety of historical information that may or may not be limiting for theater deployment. According to USCENTCOM guidelines, the following psychiatric conditions are theater limiting: ${ }^{2}$

a. Psychiatric disorders under treatment with fewer than 3 months of demonstrated stability. b. Clinical psychiatric disorders with residual symptoms that impair duty performance.

c. Mental health conditions that pose a substantial risk for deterioration and/or recurrence of impairing symptoms in the deployed environment.

d. Chronic medical conditions that require ongoing treatment with antipsychotics, lithium, or anticonvulsants.

History of psychiatric hospitalizations, suicide attempts, substance abuse or treatment and traumatic brain injuries require evaluation by competent medical authority authorized to make deployability determinations. Waiver requests may be submitted when appropriate and should include the results and recommendations from a competent mental health professional. Any condition that markedly impairs an individual's daily function is grounds for disapproval. Psychiatric conditions which are disqualifying for deployment and are not waiverable are psychotic and bipolar disorders. ${ }^{2}$

The purpose of this study was to evaluate the prevalence of preexisting mental health conditions in patients necessitating theater evacuation, comparing this rate to those who were retained and treated in theater to determine the effectiveness of these screening measures.

\section{Methods and materials}

Expeditionary Medical Facility Kuwait (EMFK) serves as an inpatient medical facility for USCENTCOM's Area of Responsibility for Southern Iraq and Kuwait as well as outpatient treatment facility serving a numerically dynamic population of approximately 22,000 personnel. This facility comprised a central medical facility and three outlying medical clinics that provided primary care services to geographically separate populations. EMFK's primary treatment site was utilized for the following analysis.

Institutional Review Board approval was gained prior to retrospective data collection from case files of patient evaluated at the EMFK mental health department from January 2010 until August 2010. Case files were reviewed for documentary evidence of professional mental health treatment or prior inpatient psychiatric treatment that pre-dated combat theater deployment. Retrospectively, those patients with prior treatment were assessed to determine if, in retrospect, this treatment would have been considered a deployment limiting mental health condition. ${ }^{2}$

Patient completed intake questionnaires were reviewed for the presence of signed releases of information for research purposes. Records not containing a signed release were excluded from analysis and files containing signed releases were included in the analysis. Demographic data on age, gender and rank as well as history and extent of pre-deployment mental health treatment were retrieved on patients who were seen even once for initial psychiatric evaluation. The patients necessitating mental health theater evacuation were then collated against those retained and treated in theater.

To determine the relative burden of mental health evacuation upon the aeromedical evacuation system and to compare against historical data, data by medical specialty on evacuations from EMFK was retrieved. Grouped data for medical evacuations by medical specialty (without identifying information) was obtained for all patients evacuated from EMFK from October 2009 through September 2010 as a demonstrator of overall mental health morbidity as well as to demonstrate the rates of mental health evacuations in corollary to the incidence of theater suicide completions during the study period. 


\section{Results}

During the study period, there were 821 patients seen at least once by a mental health professional for evaluation and treatment at EMFK. The primary hospital location saw 670 unique new patients and the outlying camp saw 174 new patients while referring 23 to the primary hospital location for further care. There were 592 patients medically evacuated from EMFK from October 2009 until September 2010. To represent the proportion of patients medically evacuated from theater for mental health conditions, a one year review of theater evacuated patients was collected. Over the one year reporting period, 18 percent of patients evacuated from EMFK were categorized as having a primary reason for evacuation as mental health. Theater evacuation by other than aeromedical means was utilized in cases deemed stable enough for theater removal (i.e. commercial air transport or tour curtailment), thus obviating the need for the formal aeromedical evacuation system activation. Thus, the 18 percent mental health aeromedical evacuation rate under-represents the proportion medically evacuated for psychiatric concerns during the study period.

Table 1 demonstrates the demographic data for the 634 available patients included in this study for chart review. Males accounted for 73.8 percent of participants, and females for 26.2 percent of evaluated patients. Mean and median ages were similar between the medically evacuated patients and those treated in theater.

Table I Demographic Data

\begin{tabular}{|c|c|c|}
\hline & $\begin{array}{l}\text { In-theater } \\
\text { Treatment Control } \\
\text { Group }\end{array}$ & $\begin{array}{l}\text { Psychiatrically } \\
\text { Evacuated Study } \\
\text { Group }\end{array}$ \\
\hline $\begin{array}{l}\text { Number of patients } \\
\text { in study }\end{array}$ & 511 & 123 \\
\hline Age (Mean/Median) & 30.1 years $/ 29.0$ years & $29 / 28.8$ years \\
\hline Male/Female & 468/I 66 (73.8\% Male) & $93 / 30(75.6 \%$ Male $)$ \\
\hline Median Rank (Range) & E4 (range EI-05) & E4 (range EI-05) \\
\hline $\begin{array}{l}\text { Prior Psychiatric } \\
\text { Hospitalizations }\end{array}$ & 5 of $5 \mathrm{II}(1.0 \%)$ & 13 of $123(10.6 \%)$ \\
\hline “MOD-10 Failures" & 10 of $511(2.0 \%)$ & 63 of $123(5 \mathrm{I} .2 \%)$ \\
\hline $\begin{array}{l}\text { Prior Mental Health } \\
\text { Treatment }\end{array}$ & 268 of $511(52.4 \%)$ & 77 of $123(62.6 \%)$ \\
\hline
\end{tabular}

Of the 634 study participants who met inclusion criteria, 123 eventually were medically evacuated from combat theater due to mental health concerns, leaving 511 who remained in theater for continued treatment and management. Ranks of the evaluated patients ranged from the most junior enlisted to senior ranking officers with the median rank of treated patient being E-4.

Rates of pre-deployment mental health treatment (defined as receiving any form of professional level counseling or treatment at any time in their life history) were determined by clinical questionnaire, detailed clinical interview and review of theater medical databases. 345 of the 634 (54.4 percent) study participants endorsed a history of priormental health treatment that pre-dated their deployment. 123 of the 634 were evacuated from theater with $77(62.6 \%)$ with predeployment mental health treatment compared to $52.4 \%$ in the nonevacuated group. 18 of the 634 were found to a history of psychiatric hospitalization pre-dating deployment, with 13 of the $123(10.6 \%)$ evacuated and 5 of the $511(1 \%)$ treated in theater. The Odds Ratio of being evacuated for mental health reasons was increased if one had a previous psychiatric admission (OR $11.96,95 \%$ CI 4.18 to 34.24 ).

To better understand the potential impact on mental health theater evacuation, retrospective application of each case was completed to determine if the prior mental health treatment would have been considered a Theater Limiting Medical Condition. Review of the 345 charts with prior mental health treatment found that 73 would have precluded theater deployment based upon the USCENTCOM MOD-10 criteria (i.e. prior inpatient psychiatric treatment, prior suicide attempts, current antipsychotic treatment, prior drug/alcohol treatment et al). The 73 patients deemed to be "Mod-10 failures" indicated only one theater waiver (only one of the 73 patients who should have had a waiver of the medical standard had it reportedly submitted but not confirmed prior to deploying) as evidenced by the records provided. Further review of the records indicated that ten of the 73 Mod-10 failures were retained in theater ( 2 percent of theater treated patients), and 63 (50.1 percent of medically evacuated patients) were eventually medically evacuated for mental health concerns. The Odds Ratio was 52.61 for being evacuated from theater if one had a MOD-10 screening failure compared to those who were not evacuated (OR 52.605, 95\% CI 25.63-107.95). The cost of these evacuations goes beyond the personal experience of the soldier evacuated, as each psychiatric theater evacuation requires a command escort of a unit member. Thus, combat effectiveness through theater attrition of combat warriors and loss of unit integrity to support these evacuations is an unquantifiable loss to combat operations.

\section{Discussion}

Medical screening for mental suitability is not new to military service. Cardona and Ritchie ${ }^{12}$ reviewed the history of military enlistment screening for mental health issues and describe a history that betrays the value of detailed psychological screening for enlistment. However, their work suggested that longitudinal functional histories and assessment of capacity under realistic conditions were considered more reliable. The Department of Defense published guidance for deployment limiting medical conditions offers service specific flexibility. ${ }^{1}$ The US Army Central Command provided it's guidance to combat theater deployment limiting medical and psychiatric conditions since the beginning of Operation Iraqi Freedom and has provided modifications over time to improve the effectiveness of these screening measures to protect both the individual warrior as well as the organization against in-theater losses. ${ }^{2}$ Based upon this limited study, enforcement of these policies appears to need refinement to ensure that adequate pre-deployment screening and application of the standards are uniformly applied.

Based upon the study information, there is a clear differentiation in outcomes from personnel who entered combat theater operations with theater limiting psychiatric conditions. Based upon the results of this study population, patients who entered theater with disqualifying mental health conditions demonstrated less theater sustainability compared to those who did not. There was a demonstrated strong correlation between "MOD-10 Failures"2 and theater evacuation with an Odds ratio of being evacuated with a history of a "Mod-10" psychiatric condition being 52 times more likely to be evacuated. Further, a history of prior inpatient psychiatric hospitalization increased the relative odds of theater psychiatric evacuation by 11 times. Based upon the findings of this study, it appears that proper application of these standards could potentially improve the outcomes for the patients and alleviate the burden of theater evacuations upon theater deployed personnel and war fighting units. Again, the information needed that could potentially influence these decisions would need to be available prior to theater deployment which is a limitation due to patient disclosure and access to medical records that can be a challenge in Reserve and National Guard units. Potential confounders to this data are obvious including the self-reporting bias 
and limitations to substantiate claims in the deployed environment as well as the patient's forthright declaration of their mental health histories prior to deployment. However, adequate record reviews of the military medical records system (utilized by all DoD medical services as a unified system) as well as adequate screening measures could potentially be improved and standards applied.

There was a statistically significant difference in the incidence of prior formal mental health treatment in those who were eventually needing theater evacuation. However, the value of this association, although statistically significant $(\mathrm{P}<.045)$, paled in comparison to those who had MOD-10 Failures and were medically evacuated from theater $(\mathrm{P}<.0001)$ with a an Odds Ratio of 52.6 indicating that this factor is highly predictive of outcomes, yet is confounded by the large ranges of confidence interval. This finding is further highlighted by the prevalence of 10 percent of aeromedically evacuated patients who had prior inpatient psychiatric treatment compared to 1 percent in the population deemed stable for continued in-theater treatment. The Odds Ratio of being psychiatrically evacuated from theater indicated patients were 11times more likely to be evacuated from theater if they had a prior inpatient psychiatric hospitalization. This finding again supports screening of patients and judicious use of waiver application.

The study population of Kuwait is a dynamic population with an estimated mean population of 22,000 beneficiaries including civilians and military transients. Attempts to determine the cost of a single aeromedical evacuation were made and were unsuccessful in determining an exact cost. However, unofficial estimates place the cost per aeromedical evacuation from combat theaters at $\$ 100,000.00$ per seat. During the reporting period, there were no suicides in this studies area of responsibility.

Suicide rates for the general population in the USA published by the Center for Disease Control (CDC) and are generally stable over time at 12 per 100,000 person-years. Military published rates in that last three years have averaged 19 per 100,000 person-years with rates as high at 30 per 100,000 person-years in deployed combat environments. The suicide and homicide completion incidence in the EMFK Area of Responsibility (AOR) during the study period was zero. Simple chance may be at play, but also one could argue that an aggressive medical evacuation stance by the medical staff, supported by the Line commanders yielded a low (non-existent) suicide and homicide rate. Given chance and probability, the calculated combat theater suicide rate for this AOR should have been 2.9 suicides during the six month period (5.8 suicides/22,000 person-years lived).

The experience of the authors is that there was a clear differentiation between patients seen for routine mental health treatment in theater to those who came with serious pre-existing mental illness that was apparent given the military psychiatric treatment record. The intent of this paper was to introduce the medical and psychiatric standards promulgated by the military services and to endorse the utilization of these time-proven standards to decrease the induced morbidity imposed by the stressors of combat theater deployments.

\section{Conclusion}

Application of currently published pre-deployment screening criteria appears supported by the findings of this study. Although historically pre-enlistment screening of military personnel for mental health issues has not demonstrated utility, ${ }^{12}$ the current system of predeployment criteria appears to demonstrate retrospective utility and potential to decrease combat theater attrition. Should these criteria be adequately applied, there is potential for the DoD to reduce the numbers of theater evacuations and the disruption caused by medical evacuation. Further, aggressive mental health evacuation standards and strong collaboration with unit Line Commanders can be risk mitigating to suicide rates in theater. Future areas of study might consider the effects of aggressive theater evacuation for mental health concerns in combat theaters as a mitigating factor to theater suicide rates, improved patient care and operational combat effectiveness.

\section{Acknowledgments}

None.

\section{Conflicts of interest}

Author declares there are no conflictas of interest.

\section{Funding}

None.

\section{References}

1. Department of Defense. Department of Defense Instruction Number 6490.07. Deployment-Limiting Conditions for Service Members and DoD Civilian Employees. 2010.

2. US CENTCOM. Modification Ten to USCENTCOM Individual Protection and Individual/Unit Deployment Policy. 2010.

3. Hayes FW. Military Aeromedical Evacuation and Psychiatric Patients during the Vietnam War. The American Journal of Psychiatry. 1969;126(5):658-666.

4. Guilford F R, Soboroff B J. Air Evacuation: An Historical Review. J Aviat Med. 1947;18(6):601-616.

5. Cohen SP, Brown C, Kurihara C, et al. Diagnoses and factors associated with medical evacuation and return to duty for service members participating in Operation Iraqi Freedom or Operation Enduring Freedom: a prospective cohort study. Lancet. 2010;375(9711):301-309.

6. Hoeffler DF, Melton LJ. Changes in the distribution of Navy and Marine Corps casualties from World War I through the Vietnam conflict. Mil Med. 1981;146(11):776-769.

7. Writer JV, DeFraites RF, Keep LW. Non-battle injury casualties during the Persian Gulf War and other deployments. Am J Prev Med. 2000;18 (suppl):64-70.

8. Harman DR, Hooper TL, Gacketetter GD. Aeromedical evacuations from Operation Iraqi Freedom: A Descriptive Study. Mil Med. 2005;170(6):521-527

9. Rundell JR. Demographics of and diagnoses in Operation Enduring Freedom and Operation Iraqi Freedom personnel who were psychiatrically evacuated from the theater of operations. Gen Hosp Psychiatry. 2006;28(4):352-356.

10. Writer KM, Adler AB, Thomas JL, et al. Predicting referral Status: Clinical Profiles in military psychological screening. Retrieved via theWalter Reed Army Institute of Research, Washington DC, USA. 2002.

11. Pols H, Oak S. War and Military Mental Health: The US Psychiatric response in the 20th Century. Am J Public Health. 2007;97(12):2132-2142.

12. Cardona RA, Ritchie EC. U.S. military enlisted accession mental health screening: history and current practice. Mil Med. 2007;172(1):31-35. 